\title{
Antibacterial activity of indole alkaloids from Aspidosperma ramiflorum
}

J.C.A. Tanaka ${ }^{1}$,

C.C. da Silva ${ }^{1}$, A.J.B. de Oliveira ${ }^{2}$, C.V. Nakamura ${ }^{3}$ and B.P. Dias Filho ${ }^{3}$

\author{
'Departamento de Química, \\ ${ }^{2}$ Departamento de Farmácia e Farmacologia, \\ ${ }^{3}$ Departamento de Análises Clínicas, \\ Universidade Estadual de Maringá, \\ Maringá, PR, Brasil
}

\begin{abstract}
Correspondence
A.J.B. de Oliveira

Departamento de Farmácia e

Farmacologia, UEM

Av. Colombo, 5790

87020-900 Maringá, PR

Brasil

Fax: +55-44-3263-6231

E-mail: ajboliveira@uem.br

Research supported by CNPq,

Fundação Araucária, and CAPES.

$\ldots \ldots \ldots \ldots \ldots \ldots$
\end{abstract}

Received May 18, 2005

Accepted December 16, 2005

\begin{abstract}
We evaluated the antibacterial activities of the crude methanol extract, fractions (I-V) obtained after acid-base extraction and pure compounds from the stem bark of Aspidosperma ramiflorum. The minimum inhibitory concentration (MIC) was determined by the microdilution technique in Mueller-Hinton broth. Inoculates were prepared in this medium from 24-h broth cultures of bacteria $\left(10^{7} \mathrm{CFU} / \mathrm{mL}\right)$. Microtiter plates were incubated at $37^{\circ} \mathrm{C}$ and the MICs were recorded after $24 \mathrm{~h}$ of incubation. Two susceptibility endpoints were recorded for each isolate. The crude methanol extract presented moderate activity against the Gram-positive bacteria B. subtilis (MIC $=250 \mu \mathrm{g} /$ $\mathrm{mL}$ ) and $S$. aureus (MIC $=500 \mu \mathrm{g} / \mathrm{mL}$ ), and was inactive against the Gram-negative bacteria E. coli and P. aeruginosa (MIC > $1000 \mu \mathrm{g} /$ $\mathrm{mL}$ ). Fractions I and II were inactive against standard strains at concentrations of $\leq 1000 \mu \mathrm{g} / \mathrm{mL}$ and fraction III displayed moderate antibacterial activity against $B$. subtilis (MIC $=500 \mu \mathrm{g} / \mathrm{mL}$ ) and $S$. aureus $(\mathrm{MIC}=250 \mu \mathrm{g} / \mathrm{mL}$ ). Fraction IV showed high activity against B. subtilis and S. aureus (MIC $=15.6 \mu \mathrm{g} / \mathrm{mL}$ ) and moderate activity against $E$. coli and $P$. aeruginosa (MIC $=250 \mu \mathrm{g} / \mathrm{mL}$ ). Fraction V presented high activity against $B$. subtilis (MIC $=15.6 \mu \mathrm{g} / \mathrm{mL}$ ) and $S$. aureus ( $\mathrm{MIC}=31.3 \mu \mathrm{g} / \mathrm{mL}$ ) and was inactive against Gram-negative bacteria (MIC $>1000 \mu \mathrm{g} / \mathrm{mL}$ ). Fractions III, IV and V were then submitted to bioassay-guided fractionation by silica gel column chromatography, yielding individual purified ramiflorines A and B. Both ramiflorines showed significant activity against $S$. aureus (MIC $=25$ $\mu \mathrm{g} / \mathrm{mL}$ ) and E. faecalis (MIC $=50 \mu \mathrm{g} / \mathrm{mL}$ ), with $\mathrm{EC}_{50}$ of 8 and $2.5 \mu \mathrm{g} /$ $\mathrm{mL}$ for ramiflorines A and $\mathrm{B}$, respectively, against $S$. aureus. These results are promising, showing that these compounds are biologically active against Gram-positive bacteria.
\end{abstract}

Antimicrobial resistance continues to grow quickly among key microbial pathogens such as Staphylococcus aureus, Pseudomonas spp, Streptococcus spp, and Enterobacteriaceae (1-3) all around the world. Development of new antimicrobial agents is
Key words

- Aspidosperma ramiflorum

- Antibacterial activity

- Monoterpenoid indole alkaloids

- Ramiflorines A and B 
tance is becoming an increasing public health problem. Bacterial resistance to almost all available antibacterial agents has been reported. The pharmaceutical industry and biotechnology companies are intensifying efforts to discover novel antibacterial agents in attempts to overcome bacterial resistance.

The search for and use of drugs and dietary supplements derived from plants have accelerated in recent years (4). Ethnopharmacologists, botanists, microbiologists, and natural-product chemists are combing the Earth for phytochemicals and "leads" which could be developed for the treatment of infectious diseases. According to Cowan (4), while 25 to $50 \%$ of current pharmaceuticals are derived from plants, none are used as antimicrobial agents. Plants produce highly bioactive molecules that allow them to interact with other organisms in their environment. Many of these substances are important in the defense against herbivores and contribute to the resistance to diseases (4). Plants, therefore, can be promising sources of antimicrobial agents.

Plants are widely employed in folk medicine, mainly in communities with inadequate conditions of public health and sanitation. Several medicinal plants have been extensively studied in order to find more effective and less toxic compounds. Aspidosperma species commonly grow in tropical America, with trees 2 to $60 \mathrm{~m}$ in height growing in a variety of habitats from the dry fields of south-central Brazil, Paraguay, and Argentina to the inundated river margins of the Amazon basin, and at elevations from a few meters above sea level to approximately 2000 $\mathrm{m}$ in eastern Peru and Bolivia (5). Extracts of parts of these plants have been used in traditional medicine for liver disorders, colds with fever, and as analgesics (6).

In the screening of a series of medicinal plants from Surinam for antimicrobial activity, extracts of three Aspidosperma species were among the most active antimicrobial samples (7). In their preliminary report (7), these investigators mentioned that the compounds detected in A. marcgraviarum and $A$. excelsum were dimeric monoterpenoid indole alkaloids identical to aspidexcine and aspidexcelsine. Furthermore, they identified other alkaloids such as tetrahydrosecamine and decarbomethoxytetrahydrosecamine.

The present study of the antibacterial activity of A. ramiflorum is part of our program directed at the investigation of new active extracts and the isolation of antiprotozoal and antimicrobial compounds from Brazilian plants $(8,9)$. The antibacterial activity of ethanolic extracts from the stem bark of $A$. dispermum, A. olivaceum, A. pyrifolium, A. pyricolum, A. polyneuron, and A. ramiflorum has been determined (8). A. ramiflorum Muell. Arg. (Apocynaceae), commonly known as "guatambu", is a tree which grows from 12 to $30 \mathrm{~m}$ in height and is native to the forests of Southeastern Brazil (10), and the extract of its bark was the most active. Some alkaloids, including ramiflorines A and B, have been previously isolated from the stem bark of A. ramiflorum (11) but these ramiflorines have not been studied for antimicrobial activity.

The present paper deals with activityguided fractionation of the crude methanolic extract of A. ramiflorum Muell. Arg. stem bark, followed by isolation and identification of active fractions and compounds. The stems of A. ramiflorum Muell. Arg. were collected in the Horto Florestal de Maringá, September 2003, in Maringá, State of Paraná, Brazil. An exsiccate (HUM 8363) of the plant collected and identified was deposited and authenticated in the Herbarium of the State University of Maringá, Maringá, PR, Brazil.

The air-dried stem of the plant (1000 g) was extracted at room temperature with methanol $(\mathrm{MeOH})$. After removal of $\mathrm{MeOH}$ by evaporation, $28.96 \mathrm{~g}$ crude extract was obtained, which was added to a $10 \%$ acetic acid solution and kept at $5^{\circ} \mathrm{C}$ overnight. The material insoluble in $10 \%$ acetic acid (frac- 
tion I, $4.89 \mathrm{~g}$ ) was filtered and the aqueous phase obtained was first extracted with chloroform $\left(\mathrm{CHCl}_{3}\right.$ - fraction II, $\left.0.51 \mathrm{~g}\right)$. The $\mathrm{pH}$ was then increased to 7 , and a neutral precipitate was obtained (fraction III, $7.04 \mathrm{~g}$ ) and extracted with $\mathrm{CHCl}_{3}$ (fraction IV, 0.24 g). The $\mathrm{pH}$ of the remaining aqueous phase was raised to 10 and the aqueous phase was extracted with $\mathrm{CHCl}_{3}$ (fraction V, $0.06 \mathrm{~g}$ ). Finally, the aqueous phase was neutralized and lyophilized, yielding fraction VI, 16.46 g. Fractionation of fraction III, IV or V (60.0 $\mathrm{mg}$ ) on silica gel preparative thin layer chromatography $\left(\mathrm{CHCl}_{3} / \mathrm{MeOH}\right.$ 92:8) in an ammonium hydroxide atmosphere led to the isolation of ramiflorine $\mathrm{A}\left(5.8 \mathrm{mg},[\alpha]^{25} \mathrm{D}=\right.$ $+23.0^{\circ}, c=1 \mathrm{mg} / \mathrm{mL}$, ethanol) and a mixture containing ramiflorine $\mathrm{B}$ and traces of 10 methoxy-geissoschizol. Further fractionation of this mixture on silica gel preparative thin layer chromatography (chloroform/ethyl acetate/methanol/triethylamine 45.5:45.5:8:1) was performed, yielding $3.1 \mathrm{mg}$ ramiflorine B $\left([\alpha]^{25}{ }_{D}=+58.5^{\circ}, c=1 \mathrm{mg} / \mathrm{mL}\right.$, ethanol $)$. This procedure was repeated to obtain a sample for the antibacterial tests and for the identification of the compounds. The structures of ramiflorines $\mathrm{A}$ and $\mathrm{B}$, established from one- and two-dimensional nuclear magnetic resonance data, were compared to those reported in the literature (11) and are illustrated in Figure 1.

The minimal inhibitory concentrations (MICs) of all extracts and reference antibiotics were determined by microdilution techniques in Mueller-Hinton broth (Merck, São Paulo, SP, Brazil) according to NCCLS guidelines (12). Inoculates were prepared in the same medium at a density adjusted to a $0.5 \mathrm{McFarland}$ turbidity standard $\left(10^{8}\right.$ colony-forming units $(\mathrm{CFU}) / \mathrm{mL}$ ) and diluted 1:10 for the broth microdilution procedure. Microtiter plates were incubated at $37^{\circ} \mathrm{C}$ and the MICs were determined after $24 \mathrm{~h}$ of incubation. Two susceptibility endpoints were used for each isolate. The MIC is defined as the lowest concentration of com- pounds at which the microorganism tested did not demonstrate visible growth. Minimum bactericidal concentration was defined as the lowest concentration yielding negative subcultures or only one colony. Vancomycin, tetracycline, and penicillin (Sigma, St. Louis, MO, USA) were used as positive control.

Additional experiments were performed to obtain information about the antimicrobial activity of the extracts. A sensitive radial diffusion technique was used as described earlier (12). Ramiflorines A and B were tested against $S$. aureus using a solid agarose medium. The agarose layer consisted of $30 \mathrm{mg} / 100 \mathrm{~mL}$ tryptic soy broth system in $10 \mathrm{mM}$ phosphate buffer, $\mathrm{pH} 7.2$, with $0.02 \%$ Tween 20 and a $0.8 \%$ GTG agarose phase (Sigma). Each well was loaded with a $10-\mu \mathrm{L}$ sample containing various amounts of ramiflorines (range $2 \ldots 10,15$, $20,25,50 \mu \mathrm{g}, \mathrm{C}-$ and $\mathrm{C}+$ negative and positive controls, respectively). The plates were incubated at $37^{\circ} \mathrm{C}$ for $16 \mathrm{~h}$ until growth of the microorganisms was visible. The diameter of the zone of complete inhibition was measured to the nearest whole millimeter.

A dose-response assay was also carried out for the individual purified ramiflorines A and B. S. aureus was grown in MuellerHinton broth to yield a suspension containing $10^{6} \mathrm{CFU} / \mathrm{mL}$, and then added to sterile tubes containing the ramiflorines to obtain final concentrations of $0.001,0.01,0.1,1$, 10,100 , and $1000 \mu \mathrm{g} / \mathrm{mL}$. Tubes were incubated at $37^{\circ} \mathrm{C}$ for $24 \mathrm{~h}$, and $\mathrm{CFU}$ were then counted for each tube.

All experiments were performed at least

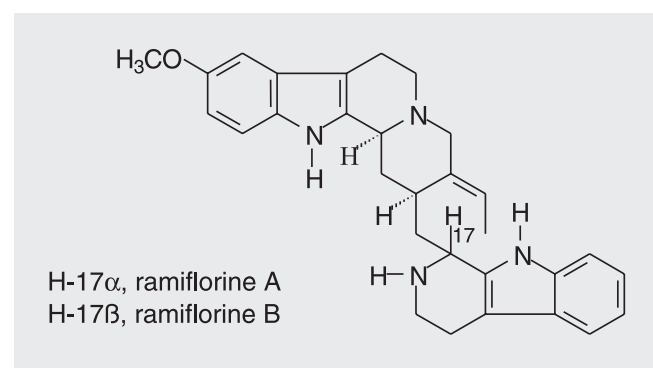

Figure 1. Structures of ramiflorines $\mathrm{A}$ and $\mathrm{B}$. 
in triplicate and each result represents the mean value \pm SEM. The mean values were compared by the Student $t$-test, with the level of significance set at $\mathrm{P}<0.05$.

The plants of the Aspidosperma genus are known to contain indole alkaloids, several of which possess important pharmacological properties $(6,13)$. These reports prompted us to carry out the separation of a crude methanol extract of $A$. ramiflorum. The separation was performed according to the usual acid-base method, which produces both an alkaloid mixture and closely related metabolites.

In the present study, the stem bark of $A$. ramiflorum was extracted with methanol. After removal of methanol, the crude extract obtained was submitted to acid-basic extraction. The in vitro results of antibacterial activities of the crude methanolic extract and fractions were classified as follows: when the MIC was $100 \mu \mathrm{g} / \mathrm{mL}$ or less, the antibacterial activity was considered to be significant, when the MIC was 100 to $500 \mu \mathrm{g} / \mathrm{mL}$ the antibacterial activity was considered moderate, when the MIC was 500 to 1000 $\mu \mathrm{g} / \mathrm{mL}$ the antibacterial activity was considered weak, and when the MIC was over 1000 $\mu \mathrm{g} / \mathrm{mL}$ the extracts were considered to be inactive. Different results were obtained for Gram-positive and Gram-negative bacteria. The methanol extract presented a moderate activity against the Gram-positive bacteria

Figure 2. Dose-response effect of ramiflorines $A$ (filled circles) and B (open circles) against Staphylococcus aureus. S. aureus was grown in MuellerHinton broth to yield a suspension containing $10^{6} \mathrm{CFU} / \mathrm{mL}$, and then added to sterile tubes containing the ramiflorines to obtain final concentrations of 0.001 , $0.01,0.1,1,10,100$, and 1000 $\mu \mathrm{g} / \mathrm{mL}$. Tubes were incubated at $37^{\circ} \mathrm{C}$ for $24 \mathrm{~h}$, and CFU were then counted for each tube. Data are reported as means \pm SEM for at least three independent experiments.
Bacillus subtilis (MIC $=250 \mu \mathrm{g} / \mathrm{mL})$ and $S$. aureus $(\mathrm{MIC}=500 \mu \mathrm{g} / \mathrm{mL}$ ), and was inactive against the Gram-negative bacteria $E s$ cherichia coli and Pseudomonas aerugino$s a$. Fractions I and II were inactive against standard strains at concentrations of $\leq 1000$ $\mu \mathrm{g} / \mathrm{mL}$. Fraction III displayed a moderate antibacterial activity against $B$. subtilis (MIC $=500 \mu \mathrm{g} / \mathrm{mL}$ ) and $S$. aureus $(\mathrm{MIC}=250 \mu \mathrm{g} /$ $\mathrm{mL})$. Fraction IV showed a strong activity against $B$. subtilis and $S$. aureus (MICs = $15.6 \mu \mathrm{g} / \mathrm{mL}$ ) and a moderate activity against the Gram-negative bacteria $E$. coli and $P$. aeruginosa $(\mathrm{MIC}=250 \mu \mathrm{g} / \mathrm{mL}$ ). Fraction V presented a strong activity against $B$. subtilis $(\mathrm{MIC}=15.6 \mu \mathrm{g} / \mathrm{mL})$ and S. aureus $(\mathrm{MIC}=$ $31.25 \mu \mathrm{g} / \mathrm{mL}$ ) and was inactive against Gramnegative bacteria (MIC $>1000 \mu \mathrm{g} / \mathrm{mL}$ ). The MICs of tetracycline for E. coli and P. aeruginosa were 1.5 and $6.2 \mu \mathrm{g} / \mathrm{mL}$, respectively. The MIC of vancomycin for B. subtilis was $0.18 \mu \mathrm{g} / \mathrm{mL}$ and the MIC of penicillin for $S$. aureus was $0.01 \mu \mathrm{g} / \mathrm{mL}$.

On the basis of these findings, the refractionation of the neutral precipitate fraction III on silica gel led to the isolation of ramiflorine A and a mixture containing ramiflorine B. Further fractionation of this mixture on silica gel was performed, yielding ramiflorine B. The structures of ramiflorines A and $\mathrm{B}$ are shown in Figure 1.

The MICs of both ramiflorines A and B were determined against the Gram-positive bacteria $S$. aureus and E. faecalis. The compounds presented MIC values of 25 and 50 $\mu \mathrm{g} / \mathrm{mL}$ for $S$. aureus and E. faecalis, respectively. Further confirmation of these results was obtained by a radial diffusion assay with $S$. aureus. The activities of ramiflorines A and $\mathrm{B}$ against the bacteria tested were assessed in agarose gel. The minimal concentration of ramiflorines that resulted in inhibition of Staphylococci growth was $2.0 \mu \mathrm{g}$. This assay was designed to achieve maximal sensitivity with minimal consumption of reagents and could be used in bioassay-guided fractionation. Prompted by these results, the 
dose-response effect of both ramiflorines A and B was tested against the Gram-positive bacterium Staphylococcus (Figure 2). The $\mathrm{EC}_{50}$, defined as the drug concentration that produced $50 \%$ of the maximal effect, were 8 and $2.5 \mu \mathrm{g} / \mathrm{mL}$ for ramiflorines $\mathrm{A}$ and $\mathrm{B}$, respectively, against $S$. aureus.

The extracts, semi-purified fractions and ramiflorines $\mathrm{A}$ and $\mathrm{B}$ showed considerable activity against Gram-positive bacteria but not against Gram-negative species. This can be explained by the fact that the outer membrane of Gram-negative bacteria is known to present a barrier to the penetration of numerous antibiotic molecules, and the periplasmic space contains enzymes which are able to degrade exogenous molecules (14). Although the mode of action of these alkaloids is not known in detail, some studies have shown that bisindole monoterpenoid alkaloids, with similar structures, act as DNA- intercalating agents or like topoisomerase inhibitors $(15,16)$.

The present results regarding the antibacterial property of $A$. ramiflorum extracts indicate that compounds from the plants of this genus could be used against the most common Gram-positive pathogens. However, these extracts and active compounds isolated from $A$. ramiflorum must be studied in animal models to determine their efficacy in vivo and possible toxicity, and to elucidate their mechanisms of action.

\section{Acknowledgments}

We are grateful to Marinete Martinez Vicentim (Departamento de Análises Clínicas, Universidade Estadual de Maringá, Maringá, PR, Brazil) for her help with the experiments.

\section{References}

1. Bax R, Mullan N \& Verhoef $F$ (2000). The millennium bugs - the need for and development of new antibacterials. International Journal of Antimicrobial Agents, 16: 51-59.

2. Bhavnani SM \& Ballow $\mathrm{CH}$ (2000). New agents for Gram-positive bacteria. Current Opinion in Microbiology, 3: 528-534.

3. Chopra I, Hawkey PM \& Hinton M (1992). Tetracyclines, molecular and clinical aspects. Journal of Antimicrobial Chemotherapy, 29: 245-277.

4. Cowan MM (1999). Plant products as antimicrobial agents. Clinical Microbiology Reviews, 12: 564-582.

5. Woodson RE (1951). Studies in the Apocynaceae VIII: An interim revision of genus Aspidosperma Mart. \& Zucc. Annals of the Missouri Botanical Garden, 38: 119-204.

6. Obitz P, Stöckigt J, Mendoz LA et al. (1997). Alkaloids from Cell Cultures of Aspidosperma quebracho-blanco. Academic Press, London, UK.

7. Verpoorte R, Ruigrow CLM \& Svendsen B (1982). Medicinal plants of Surinam. II. Antimicrobial active alkaloids from Aspidosperma marcgravianum. Planta Medica, 46: 149-152.

8. Oliveira AJB, Dias Filho BP, Nakamura CV et al. (2005). Antibacterial activity of Aspidosperma species. Fitoterapia (in press).

9. Oliveira AJB, Ferreira ICP, Leon LL et al. (2004). Antileishmanial activity of alkaloidal extract from Aspidosperma ramiflorum. Memó- rias do Instituto Oswaldo Cruz, 99: 325-327.

10. Lorenzi H (1992). Árvores Brasileiras. Plantarum, Nova Odessa, $\mathrm{SP}$, Brazil.

11. Reis FAM, Marques MFS, Kato $L$ et al. (1996). Indole alkaloids from Aspidosperma ramiflorum. Phytochemistry, 41: 963-967.

12. National Committee for Clinical Laboratory Standards (2000). Methods for Dilution Antimicrobial Susceptibility Tests for Bacteria that Grow Aerobically. Approved Standard M7-A5, NCCLS, Wayne, PA, USA.

13. Kutney JP, Noda M, Lewis NG et al. (1981). Studies in the dihydropyridine series 5 - synthesis of pyridocarbazole alkaloids - olivacine and guatambuine. Heterocycles, 16: 1469-1472.

14. Duffy CF \& Power RF (2001). Antioxidant and antimicrobial properties of some Chinese plant extracts. International Journal of Antimicrobial Agents, 17: 527-529.

15. Angenot L, Quentin-Leclercq J, Phillipson DJ et al. (1991). Antiamoebic and antiplasmodial activities of alkaloids isolated from Strychnos usambarensis. Planta Medica, 57: 337-340.

16. Bonjean K, De Pauw-Gellet MC, Defresne MP et al. (1998). The DNA intercalating alkaloid cryptolepine interferes with topoisomerase II and inhibits primarily DNA synthesis in B16 melanoma cells. Biochemistry, 37: 5136-5146. 